\title{
The inhibitory effect of TU-100 on hepatic stellate cell activation in the tumor microenvironment
}

\author{
Yuma Wada ${ }^{1, *}$, Kazunori Tokuda ${ }^{1, *}$, Yuji Morine ${ }^{1}$, Shohei Okikawa ${ }^{1}$, Shoko \\ Yamashita ${ }^{1}$, Tetsuya Ikemoto ${ }^{1}$, Satoru Imura ${ }^{1}$, Yu Saito ${ }^{1}$, Shinichiro Yamada ${ }^{1}$ and \\ Mitsuo Shimada ${ }^{1}$ \\ ${ }^{1}$ Department of Surgery, Graduate School of Biomedical Sciences, Tokushima University, Tokushima, Japan \\ *These authors contributed equally to this work \\ Correspondence to: Yuji Morine, email: ymorine@tokushima-u.ac.jp \\ Keywords: CRLM; TU-100; HSC; CRC; IL-6
}

Received: May 19, $2020 \quad$ Accepted: November 19, $2020 \quad$ Published: December 08, 2020

Copyright: @ 2020 Wada et al. This is an open access article distributed under the terms of the Creative Commons Attribution License (CC BY 3.0), which permits unrestricted use, distribution, and reproduction in any medium, provided the original author and source are credited.

\section{ABSTRACT}

Introduction: The tumor microenvironment is involved in acquiring tumor malignancies of colorectal liver metastasis (CRLM). We have reported that TU100 (Daikenchuto) suppresses hepatic stellate cell (HSC) activation in obstructive jaundice. In this study, we report new findings as the direct and indirect inhibitory effects of TU-100 on cancer cell growth through the suppression of HSC activation.

Materials and Methods: The HSCs (LX2) were cultured in colon cancer cells (HCT116 and HT29)-conditioned medium (CM) with or without TU-100 treatment (90, $270,900 \mu \mathrm{g} / \mathrm{ml}$ ). Activated HSCs (aHSCs) were detected by a-SMA and IL-6 mRNA expressions and cytokine arrays of HSC's culture supernatants. Cancer cell growth was analyzed for proliferation and migration ability, compared with TU-100 treatment. To investigate the direct anti-tumor effect of TU-100, cancer cells were cultured in the presence of aHSC-CM and TU-100 $(90,270,900)$ or aHSC-CM alone, and assessed autophagosomes, conversion to LC3-II protein, and Beclin-1 mRNA expression.

Results: Colon cancer-CM significantly increased a-SMA and IL-6 MRNA expressions of aHSC. a-SMA and IL- 6 mRNA expressions of aHSC, and IL- 6 secretions from aHSCs were significantly decreased with TU-100 $(270,900)$ treatment, compared to colon cancer-CM alone. Compared with normal culture medium, aHSC-CM led to a significantly increased cell number and modified HSC-CM (TU-100; 270, 900) significantly suppressed cancer cell growth and migration. TU-100 (900) treatment induced autophagy and significantly promoted the autophagic cell death.

Conclusions: TU-100 inhibited colon cancer cell malignant potential by both suppressing HSC activation and inducing directly autophagy of cancer cells.

\section{INTRODUCTION}

Colorectal cancer (CRC) is the second most common cause of cancer death worldwide, and the incidence is expected to increase over the next few years [1-3]. Multidisciplinary chemotherapy improves survival and becomes the standard treatments for advanced CRC $[4,5]$. Additionally, herbal medicine is considered an effective resource and important in pharmacological research and drug development [6]. Many of these compounds have been used to treat a variety of diseases in clinical, even in CRC [7].
TU-100 (Daikenchuto) is a commonly prescribed Japanese herbal medicine that has been used to treat gastrointestinal motility and prevent post-operative intestinal dysfunction providing the most preclinical and clinical efficacy in several trials [8-14]. TU-100 is a mixture of herbal medicines such as processed ginger (Zingiberis Siccatum Rhizoma), ginseng (Ginseng radix), Japanese pepper (Zanthoxylum fruit), and maltose sugar by a weight ratio of $5.6 \%, 3.3 \%, 2.2 \%, 88.9 \%$, respectively $[10,15]$. Each compound contains specific extracts such as sanshools in Japanese pepper; ginsenosides and polysaccharides in ginseng; and gingerols and shogaols 
in ginger [16]. It has been reported that TU-100 has antiinflammatory by decreasing expression of inflammatory cytokines and anti-cancer effects by inducing programmed cell death in animal model [16-21], although its mechanism is not fully known.

In the cancer microenvironment, tumor progression is associated with the interaction between cancer cells and stromal cells such as the cancer-associated fibroblast (CAF) [22-27]. It has been also well-known that in the microenvironment of colorectal liver metastasis (CRLM), hepatic stellate cells (HSCs) are activated to CAFs by cancer cells and consequently various effects of tumor malignancy such as cell proliferation, invasion and liver fibrosis are enhanced [28]. We have previously reported that TU-100 improved liver fibrosis and decreased expressions of $\alpha$-smooth muscle actin ( $\alpha$-SMA), collagen type 1 (Colla1), and tissue inhibitor of metalloproteinase 1 (Timp1) in a rat model of common bile duct ligation through the suppression of activated HSCs [29]. Given these previous findings, the aim of this study was to investigate the anticancer effect of TU-100 through the regulation of the interaction between HSCs and cancer cells.

\section{RESULTS}

\section{TU-100 inhibited HSC activation in cancer- conditioned medium}

At first, to investigate the effects of TU-100 on HSC activation in cancer-conditioned medium (cancer$\mathrm{CM}$ ) derived from 24 hours colon cancer cell culture, we assessed activated HSC (aHSC) and modified HSC (Supplementary Figure 1). Since previous studies have reported that interleukin-6 (IL-6) was a precancerous cytokine, which can promote the migration of cancer cells [30], this study also tried to check the role of IL-6 in the interaction between HSCs and cancer cells. Activated fibroblasts or myofibroblasts with $\alpha$-SMA expression are the main cellular constituents of reactive stroma in some solid tumors [31]. The HSCs are one of the vital stromal component and known to be activated or transdifferentiated through intercellular communication to become myofibroblast-like cells [32], and these activated HSCs show high expression of $\alpha$-SMA [33]. Results showed that aHSCs in cancer-CM significantly increased messenger RNA (mRNA) expressions of $\alpha$-SMA and IL-6 (Figure 1A). Meanwhile, HSCs were cultured in cancerCM with simultaneous TU-100 treatment (90: $90 \mu \mathrm{g}$ / $\mathrm{mL}, 270: 270 \mu \mathrm{g} / \mathrm{mL}$, and 900: $900 \mu \mathrm{g} / \mathrm{mL}$ ), which were called as modified HSCs, and $\alpha$-SMA and IL- 6 mRNA expressions were significantly reduced in modified HSCs with TU-100 treatment $(270,900)(p<0.05$, Figure 1B).

Cytokine arrays of the HSCs culture supernatants were carried out to determine the changes in the cytokine secretion profile of $\mathrm{HSC}$ activation in cancer-CM according to the presence or absence of TU-100 treatment. Results showed that IL-6 and vascular endothelial growth factor (VEGF) secretions from modified HSCs with TU100 (900) treatment were significantly decreased $(p<$ 0.05 , Figure $1 \mathrm{C}$ and $1 \mathrm{D})$. In addition, the IL-6 and VEGF secretions of modified HSCs with TU-100 treatment were measured in the same dose dependent manner and it was confirmed that the TU-100 $(270,900)$ treatment could downregulate IL-6 and VEGF secretions from modified HSCs, compared to cancer-CM alone (Figure 1E).

\section{TU-100 modified HSC-CM reduced cancer cell migration and proliferation}

Based on the above results, it was considered that HSCs in cancer-CM with simultaneous TU-100 treatment did not indicate the cancer cell proliferation- and migration-promoting abilities. To prove this hypothesis, 2 types of HSC-CM were produced. The HSCs were cultured for 24 hours in cancer-CM with or without TU100 treatment $(90,270,900)$. The resulting $\mathrm{CM}$ was subsequently exchanged for 2 types of HSCs (which were named aHSC and modified HSC) and obtained aHSC-CM and TU-100 $(90,270,900)$ treated HSC-CM (modified HSC-CM) after 24 hours (Supplementary Figure 2). Compared with normally cultured medium, aHSC-CM led to the significantly increased proliferation-activity of colon cancer cells (Figure 2A). Meanwhile, the TU-100 modified HSC-CM $(270,900)$ significantly suppressed the cancer cell growth and migration compared to the aHSC-CM (Figure 2A-2C). Next, an IL-6 antibody was used to neutralize the IL-6 pathway in the aHSC-CM. IL-6 neutralization significantly cancelled the ability of cancer cells migration and proliferation induced by aHSC$\mathrm{CM}$, compared with Immunoglobulin $\mathrm{G}$ (IgG) as a control (Figure 3A-3C).

\section{TU-100 directly reduced cancer malignant potential in aHSC-CM}

The anti-tumor effect of TU-100 has been demonstrated in several cancer cells and mouse models $[19,20]$. To investigate the direct anti-tumor effect of TU-100, colon cancer cells were cultured for 24 hours in the presence of aHSC-CM and TU-100 (90, 270, 900) or aHSC-CM alone (Supplementary Figure 3 ). The cell growth and migration abilities of cancer cells cultured in aHSC-CM and TU-100 (900) treatment were shown to be significantly decreased (Figure 4A-4C).

Japanese pepper and ginseng, components of TU-100 and one of the mechanisms for the direct antitumor effect of TU-100, have been reported to promote autophagic cell death in cancer cells [34-39]. Autophagy is initiated by UNC51-like kinase (ULK) 1, Beclin1 and PI3K complexes that promote the formation of an isolation membrane [40]. The isolation membrane gets decorated 
with microtubule-associated protein 1A/1B-light chain 3 (LC3) which serves as an anchor for recruiting the selected cargo. Increase in the mRNA and protein expression of several autophagy core genes and proteins such as Beclin1 and LC3 often accompany the induction of autophagy [41].

Therefore, we assessed the confirmation of autophagosomes and conversion of LC3-I to LC3-II in Western blots, besides increased mRNA expression of Beclin1 as indicators of autophagy. We detected the formation of autophagosomes in cancer cells cultured in aHSC-CM with TU-100 (900) treatment (Figure 5A). In addition, we confirmed the conversion of LC3-I to LC3-II in HT29 cultured with TU-100 (900) treatment by Western blotting (Figure 5B) and Beclin-1 mRNA expression was also increased in TU-100 (900) treatment (Figure 5C). Consequently, these results show TU-100 induce the death of autophagic cells.

\section{DISCUSSION}

Among all herbal medicines, some have been reported to have anti-tumor and anti-inflammatory effects [42-44]. TU-100 is one of the herbal medicinal extract preparations available in Japan [10]. Furthermore, TU-100 has been approved as a drug by the US Food and Drug
Administration. Our present study revealed that TU-100 inhibited tumor growth of cancer cells by suppressing HSC activation and decreasing IL-6 secretion from HSC, as well as inducing directly the autophagy of cancer cells. This has the potential to lead to clinical application and novel approach to control tumor growth in safety.

In the tumor microenvironment of CRLM, Kupffer cells and HSCs are activated by cancer cells, and those activated stromal cells interact with metastatic cancer cells and induce tumor infiltration [23]. In several reports, IL-6 has been shown to play a key role for promoting the cancer cell malignancy in the tumor microenvironment [45-47]. As we previously reported that activated HSCs promote cancer cell progression through paracrine or autocrine IL-6, it is known that secretion of CAFs and activated HSC regulate downstream pathways and promote tumor growth [48]. To overcome this aspect, we have noticed that TU-100 suppresses HSC activation and liver fibrosis in the common bile duct ligation rat model [29]. This led to focus on the possible anti-tumor effect of TU-100 to cancel the interaction between HSCs and tumor cells, and present studies have shown that TU-100 has inhibited HSC activation promoted by cancer cells, and suppressed the secretion of IL-6 in HSCs. As IL-6 secretion was showed to be most suppressed in the supernatant of HSCs with TU-100 treatment, we confirmed that anti-IL-6 antibody
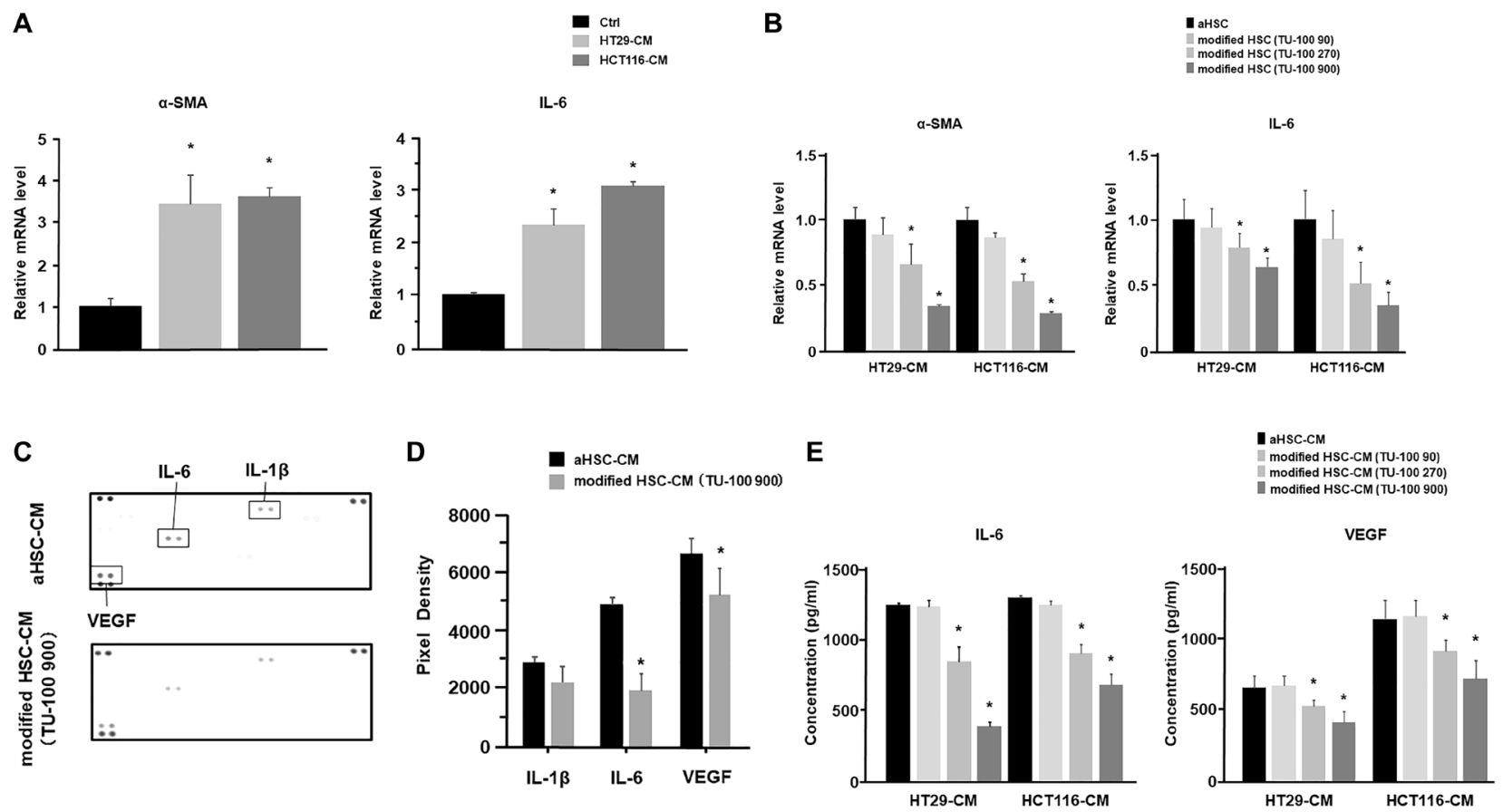

Figure 1: TU-100 inhibited HSC activation and cytokine's secretions from HSCs. (A) HSC was stimulated with cancerconditioned medium (cancer-CM) derived from the 24 hours cancer cells (HT29 and HCT116) culture or cultured with normal medium (control; Ctrl). $\alpha$-SMA and IL-6 mRNA expressions of activated HSCs in cancer-CM were analyzed by PCR analysis. (B) HSCs were cultured in cancer-CM, with simultaneous TU-100 treatment: (90: $90 \mu \mathrm{g} / \mathrm{mL} ; 270: 270 \mu \mathrm{g} / \mathrm{mL}$; and $900: 900 \mu \mathrm{g} / \mathrm{mL}$ ), as described in Supplementary Figure 1. $\alpha$-SMA and IL-6 mRNA expressions were analyzed by PCR analysis. (C) Cytokine arrays of HSC's culture supernatants (aHSC-CM) with or without TU-100 (900) treatment. (D) Pixel density of dot plots was calculated by using ImageJ software. (E) IL-6 and VEGF secretions from HSCs with or without TU-100 treatment were analyzed by ELISA. ("significantly different from Ctrl, $P<.05, n=4$. Mann-Whitney $U$ test). 
has the effect of tumor regression as well as TU-100. Although these reports supported present studies, VEGF secretion was also suppressed in the supernatant from HSC and the role of VEGF should be validated in future experiment.

Regarding as the mechanism of suppressing HSC activation, we previously reported that the suppression of the toll-like receptor 4 (TLR4) and transforming growth factor $\beta$ (TGF- $\beta$ ) showed one of the important mechanism related to the pharmacologic effect of TU-100 [29]. In other possibilities, Ginseng contained in TU-100 have reported that liver $\mathrm{X}$ receptors (LXRs), nuclear factor erythroid 2-related factor 2 (Nrf2) and janus kinase 2 (Jak2)/ signal transducer and activator of transcription 3 (Stat3) pathways are involved in HSC suppression [49, 50]. Although, it is necessary to continue investigating the mechanism of TU-100 that suppresses HSC activation, this study showed that TU-100 decreased IL-6 secretion from HSCs and inhibited cell migration and proliferation through the suppressing of HSC activation.

Additionally, this study showed the direct antitumor effect of TU-100 on cancer cells through autophagy induction. Autophagy degrades the cytoplasmic components by delivering to the lysosomes [51, 52].

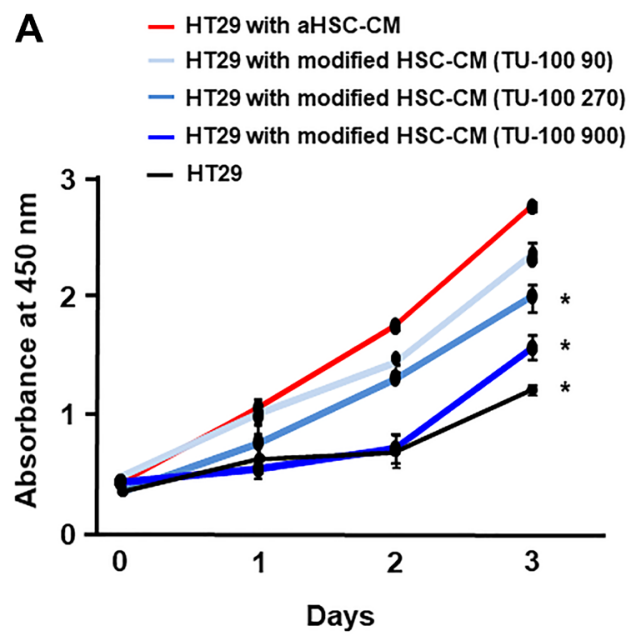

B

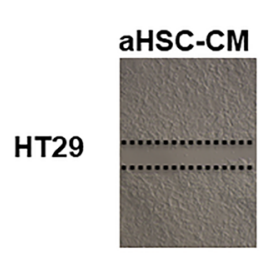

\section{$\frac{\text { Modi }}{90}$}

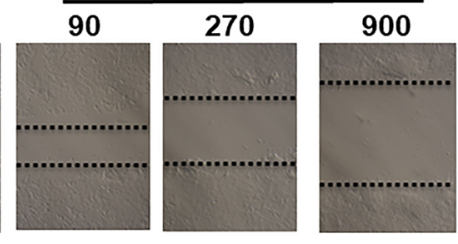

Modified HSC-CM (TU-100)

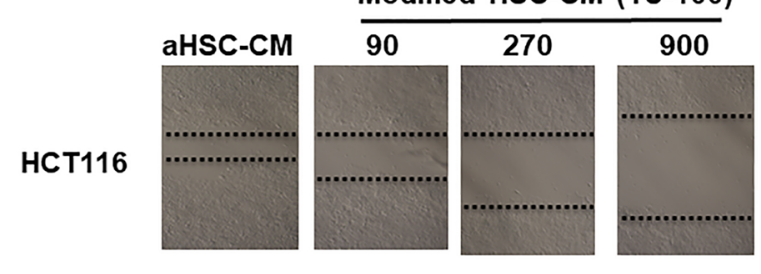

- HCT116 with aHSC-CM

- HCT116 with modified HSC-CM (TU-100 90)

- HCT116 with modified HSC-CM (TU-100 270)

- HCT116 with modified HSC.CM (TU-100 900)

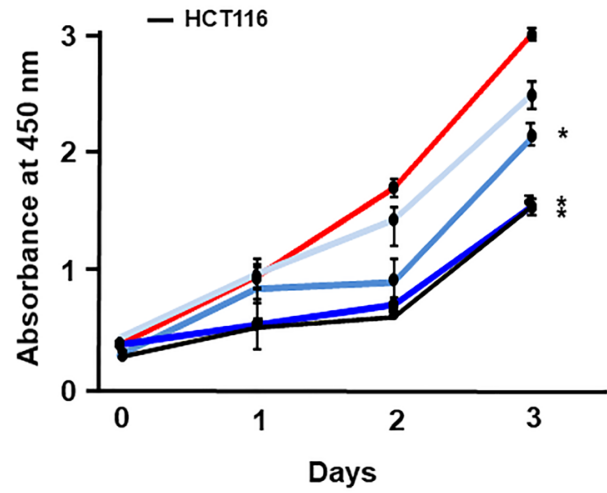

Ctrl $(\mathrm{OH})$

aHSC-CM $(24 \mathrm{H})$

modified HSC-CM (TU-100 90)

modified HSC-CM (TU-100 270)

C modified HSC-CM (TU-100 900)
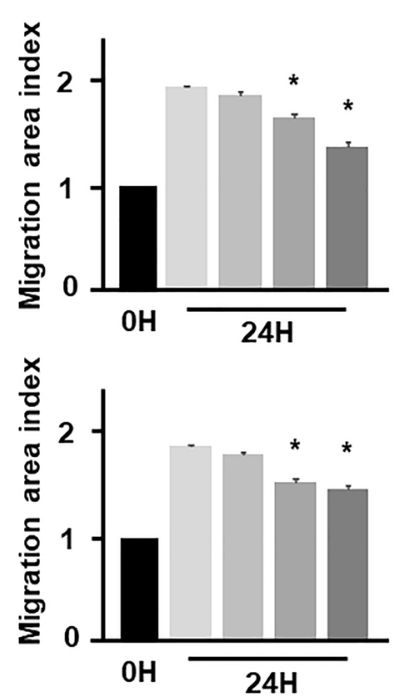

Figure 2: TU-100 modified HSC-CM reduced cancer cell migration and proliferation. Cancer cells (HT29 and HCT116) were cultured for 24 hours with aHSC-CM or modified HSC-CM as described in Supplementary Figure 2. (A) Proliferation assay and (B and $\mathbf{C}$ ) migration assay of cancer cells were monitored for 3 days and 24 hours, respectively. ( ${ }^{*}$ significantly different from aHSC-CM group without TU-100 treatment, $P<.05, n=4$, The one-way ANOVA with Turkey-Kramer's test (proliferation assay), Mann-Whitney $U$ test (migration assay). 
Cancer cells depend on autophagy than normal cells because hypoxic situation of the tumor increased the activity of autophagy $[53,54]$. Cancer cells exposed to stress maximize the energy production by upregulating autophagy and induced cell death by excessive activation of autophagy [55]. Although it is still unknown the mechanism of TU-100 to induce autophagic cell death, previous reports demonstrated that ginseng, ginger, and Japanese pepper which are contained in TU-100 induced programmed cell death like autophagy and apoptosis [34$39,56,57]$. It was reported that Japanese pepper promotes cancer cell death by inducing autophagy $[36,57]$. Ginseng metabolites which is formed in bacterial glycosidases and glucosidases have important part for an anti-tumor

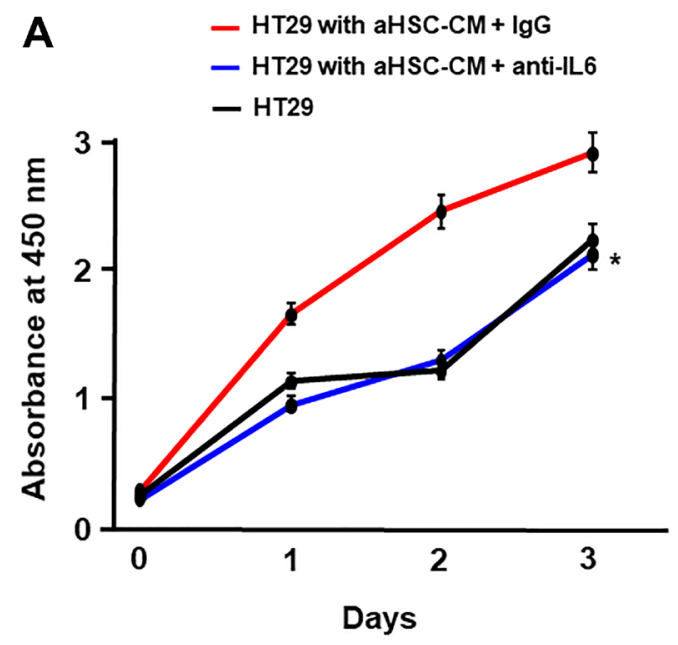

B

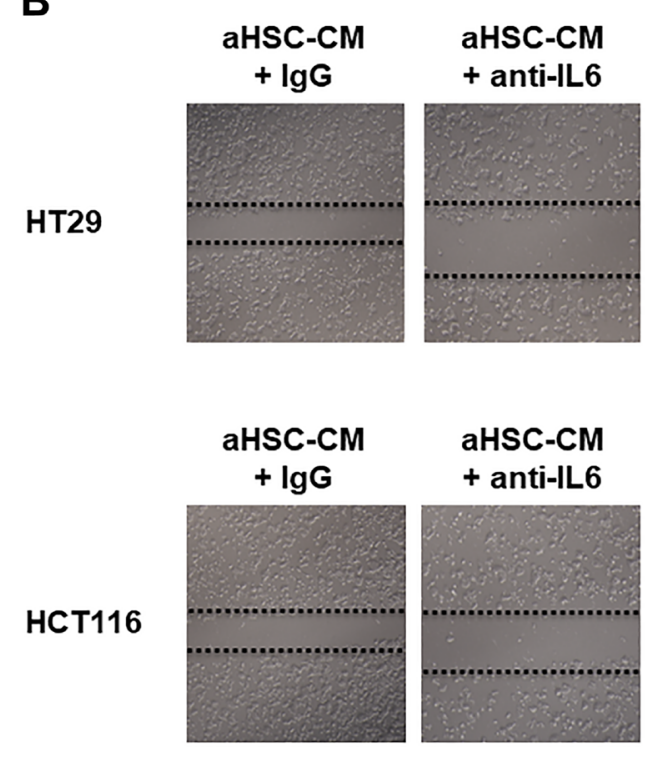

activity [58]. Ginseng triterpendanmarandine senoside $\mathrm{Rb} 1$ is deglycosylated and easily absorbed, producing compound $\mathrm{K}$ with anti-tumor activities such as cancer cell autophagy $[59,60]$. Also, ginger and ginseng have been reported to block Akt and extracellular-regulated kinase (ERK) signaling [20]. In addition, TU-100 reduced the expression of reactive oxygen species (ROS), $\beta$-catenin and Hes-1 which plays an important role in various cellular responses, like autophagy [20]. Although these reports have favoured our results, the mechanism of cell death in TU-100 should be performed in future experiment.

In summary, this study has shown that TU-100 inhibited the malignant potential of cancer cells by both suppressing HSC activation and secretion of IL-6 from
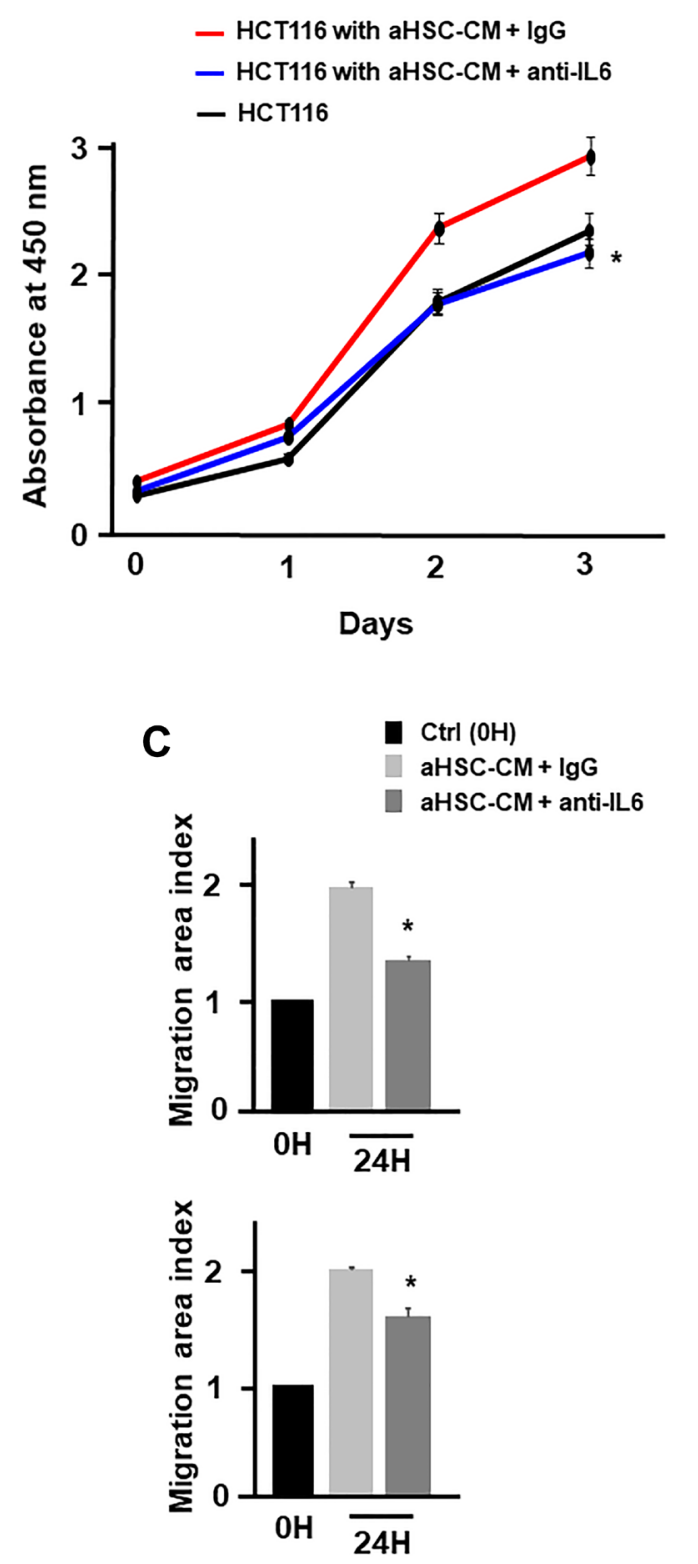

Figure 3: HSC derived from IL-6 promoted cancer cell proliferation and migration. (A) Proliferation assay and (B and C) migration assay of cancer cells in aHSC-CM with or without an IL-6 antibody were monitored for 3 days and 24 hours, respectively. ('significantly different from aHSC-CM group without IL-6 neutralization, $P<.05, n=4$, The one-way ANOVA with Turkey-Kramer's test (proliferation assay), Mann-Whitney $U$ test (migration assay). 
HSCs, and inducing directly the autophagy of cancer cells. These results demonstrate that TU-100 could be one of the promising therapeutic agent for the treatment of CRLM.

\section{MATERIALS AND METHODS}

\section{Cell culture}

The human colorectal cancer cell lines (HCT116 and HT29) were originally obtained from the American Type Culture Collection (ATCC, Manassas, VA, USA). The human HSC line (LX2) was obtained from Sigma-Aldrich (St Louis, MO, USA). Cancer cell lines were maintained in McCoy's 5A Medium (Life Technologies Ltd. Tokyo, Japan) containing 10\% fetal bovine serum (FBS) (Life Technologies Ltd.) and incubated at $37^{\circ} \mathrm{C}$ in a humidified $5 \%$ CO2. The HSCs were maintained in Dulbecco's Modified Eagle Medium (DMEM) (Life Technologies Ltd.) containing $10 \% \mathrm{FBS}$ and incubated at $37^{\circ} \mathrm{C}$ in a humidified $5 \% \mathrm{CO} 2$.

\section{Cell preparation with conditioned medium (CM)}

Cancer cells $\left(3.0 \times 10^{6}\right.$ cells $)$ were maintained in McCoy medium with $1 \%$ FBS for 24 hours in a $10 \mathrm{~cm}$ dish. Then, we discarded the supernatant and cancer cells were cultured in the medium of HSCs $\left(3.0 \times 10^{5}\right.$ cells $)$ for 24 hours. After that, the procedure for a FBS-free medium was cultured. After 24 hours, the supernatant was collected, centrifuged at $450 \times \mathrm{g}$ for 5 minutes and filtrated using a $0.2 \mu \mathrm{m}$ filter [61]. The CM was added without any additional FBS. For the IL-6 of CM neutralization, IL-6 antibody (7270-IL; R\&D Systems, Minneapolis, MN) was added to the CM with a concentration of $0.2 \mu \mathrm{g} / \mathrm{mL}$ and incubated for 1 hour.

\section{Reagents}

TU-100 was obtained from Tsumura \& Co (Tsumura Daikenchuto Extract Granules; Tsumura \& Co, Tokyo, Japan). As previously noted, TU-100 is an extract powder

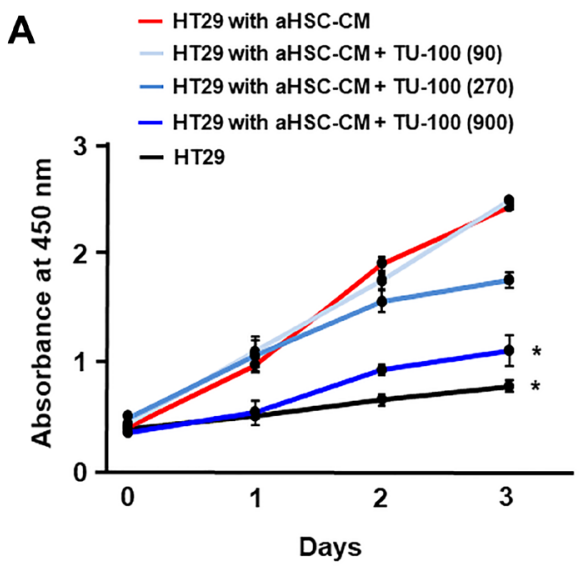

B
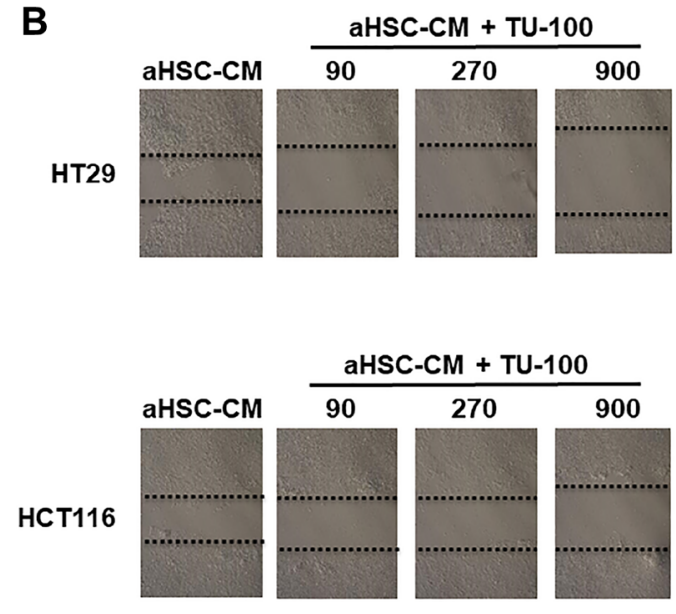

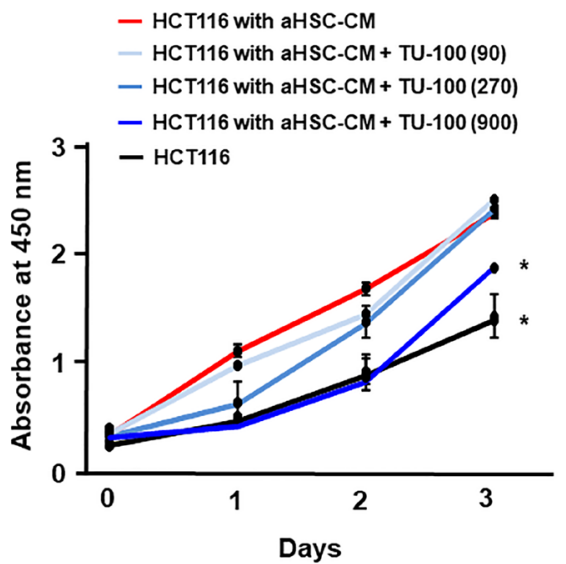

C

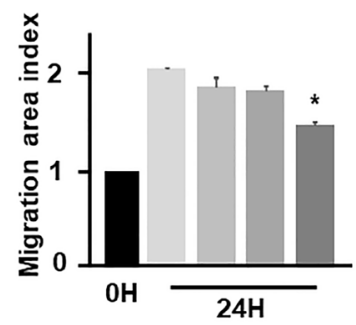

Ctrl $(\mathrm{OH})$ aHSC-CM (24H) aHSC-CM + TU-100 (90) aHSC-CM + TU-100 (270) HT29

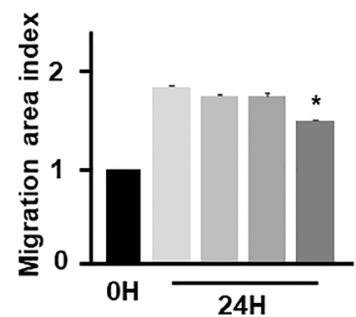

Figure 4: TU-100 directly reduced cancer malignant potential in activated HSC conditioned. Colon cancer cells (HT29 and HCT116) were cultured for 24 hours in aHSC-CM with or without simultaneous TU-100 $(90,270,900)$ treatment as described in Supplementary Figure 3. (A) Proliferation assay and (B, C) migration assay of cancer cells cultured in aHSC-CM with or without TU-100 treatment were monitored for 3 days and 24 hours, respectively. ("significantly different from aHSC-CM group without TU-100 treatment, $P<.05, n=4$, The one-way ANOVA with Turkey-Kramer's test (proliferation assay), Mann-Whitney $U$ test (migration assay). 
from a mixture of Japanese pepper (Zanthoxylum fruit), processed ginger (Zingiberis Siccatum Rhizoma), and ginseng (Ginseng radix) [10, 16, 62]. The each concentrations of TU-100 (90, 270, and $900 \mu \mathrm{g} / \mathrm{mL})$ were added to the medium using the previously described method $[15,17,29,63]$.

\section{Cell proliferation assay}

Cell proliferation assays were performed with a Cell Counting Kit-8 (CCK8) (Dojindo Molecular Technologies, Inc. Kumamoto, Japan). Cancer cells were plated in 24 well plates and incubated with $10 \%$ CCK8-CM for 2 hours. The cells were measured by using the plate reader (SpectraMax i3, Molecular Devices, Tokyo, Japan) at the absorbance $450 \mathrm{~nm}$. We used IgG (Cat\#1-001-A, R\&D Systems) as a control.

\section{Scratch assays}

For scratch assays, cancer cells $\left(3.0 \times 10^{6}\right.$ cells $)$ were plated in $6 \mathrm{~cm}$ dishes. The medium of cancer cells $(3.0 \times$ $10^{6}$ cells) was transferred to activated HSCs conditioned medium (aHSC-CM) or DMEM medium (control) and

A

HT29

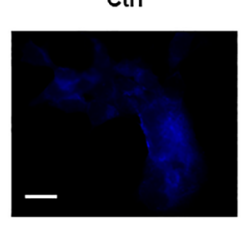

Ctrl

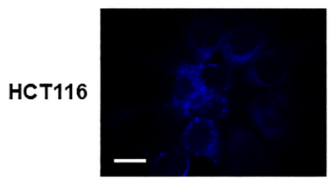

B

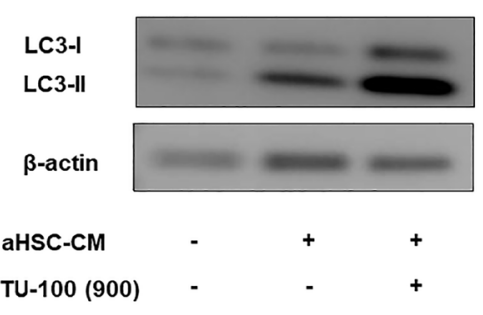

C

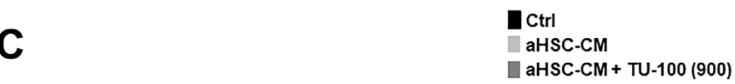

Beclin-1

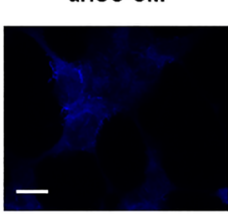

aHSC-CM

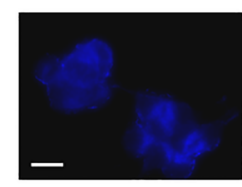

aHSC-CM + TU-100 (900)

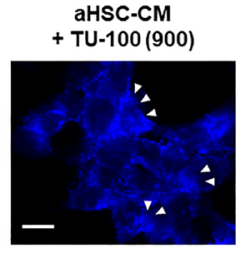

aHSC-CM + TU-100 (900)

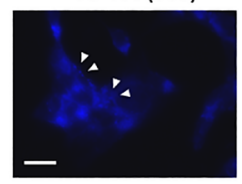

atrl

aHSC-CM

aHSC-CM + TU-100 (900)
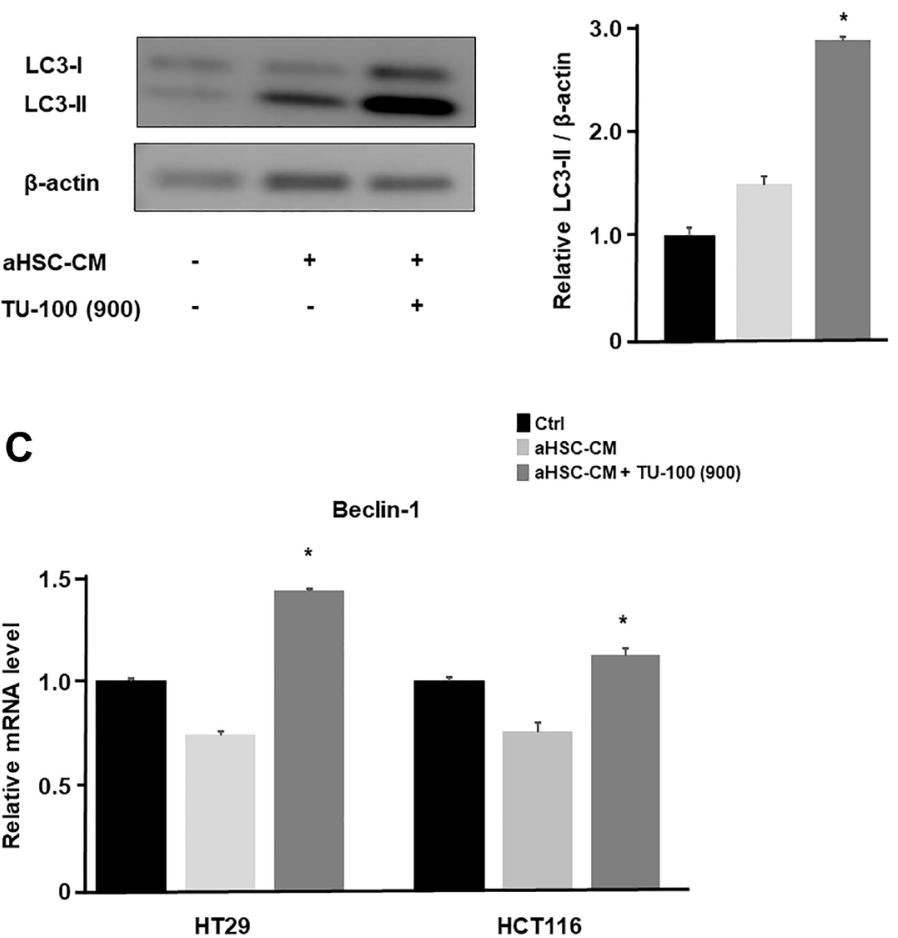

Figure 5: TU-100 induced the autophagic cell death. (A) To assess autophagosomes, colon cancer cells (HT29 and HCT116) in aHSC-CM with or without TU-100 (900) treatment were stained with blue dots in autophagic vacuoles (blue) and DAPI (blue). Arrowhead; bright blue dots indicate autophagy. Scale bar, $10 \mu \mathrm{m}$. (B) Western blotting of LC3-I and LC3-II in HT29 cultured HSC's supernatants (aHSC-CM) with or without TU-100 (900) treatment. (C) Beclin-1 mRNA expressions of cancer cells were detected by PCR analysis. ('significantly different from aHSC-CM group without TU-100 treatment, $P<.05, n=4$, Mann-Whitney $U$ test). 
cultured for 24 hours. When cells are confluent, a plastic pipette tip was used to make 1-mm-wide area. After culturing for 24 hours in a medium with $1 \%$ FBS, wound closure was monitored by microscope under phase to measure the wound area [64].

\section{Enzyme-linked immunosorbent assay}

The levels of IL-6 and VEGF were detected by using IL-6 and a VEGF Quantikine ELISA kit (R\&D Systems). The wavelength was measured at $450 \mathrm{~nm}$ using a plate reader (SpectraMax i3; Molecular Devices) as a detection of emission at a wavelength of $540 \mathrm{~nm}$.

\section{Polymerase chain reaction analysis}

Total RNA was extracted from each cell using the RNeasy Mini Kit (Qiagen, Hilden, Germany). Synthesis of complementary DNA was conducted using the reverse transcription kit (Applied Biosystems, Thermo Fisher Scientific Inc., Waltham, MA, USA). The primer sequences from TaqMan gene expression assays (assay identification number) for the target genes used in the present study are shown as followed: $\alpha$-SMA (Hs05005341_m1); IL-6 (Hs00174131_m1) and Beclin-1 (Hs01061917_g1). The relative abundance of target transcripts was evaluated and normalized to the expression of Glyceraldehyde-3-Phosphate Dehydrogenase (GAPDH) (4352339E) as an internal control. Real-time quantitative reverse transcription polymerase chain reaction (RT-qPCR) analysis was performed on the StepOnePlus Real-Time PCR System (Applied Biosystems).

\section{Cytokine array}

Supernatants of the aHSCs with or without TU$100(900 \mu \mathrm{g} / \mathrm{mL})$ treatment were collected, and the debris was eliminated through a $0.2 \mu \mathrm{m}$ filter. Cytokine detection in the supernatants was performed using a Proteome Profiler Human Cytokine Array Kit (ARY005B; R\&D Systems). Array membranes were spotted by each capture antibodies and incubated with samples overnight at $4{ }^{\circ} \mathrm{C}$. After incubation, the membranes were washed three times, and incubated with streptavidin- horseradish peroxidase (HRP)-coupled antibody at room temperature for 30 minutes. Then, the membranes were incubated with Chemiluminescent reagents for 1 minute, and the intensity of the chemiluminescent reaction on the membranes was detected by chemiluminescence (GE Healthcare, Little Chalfort, UK). The relative level of cytokine was determined by measuring the density of each spot for comparison with those variables of negative and positive standards.

\section{Detection of autophagosomes}

Autophagosomes were detected by using a Cell Meter ${ }^{\mathrm{TM}}$ Autophagy Assay kit Blue (AAT Bioquest, Inc.,
Sunnyvale, CA, USA) in HT- 29 and HCT-116 with TU$100(900 \mu \mathrm{g} / \mathrm{mL})$. Treated with TU-100 and negative control cells were cultured with Autophagy Blue ${ }^{\mathrm{TM}}$ working solution and incubated at $37^{\circ} \mathrm{C}$ for 1 hour. Cancer cells were washed for three times, and then examined under a BZ-x700 fluorescence microscope (Keyence, Osaka, Japan).

\section{Western blotting}

Cells were collected and lysed in RIPA buffer (Thermo Fisher Scientific Inc.) supplemented with protease inhibitor cocktail (Sigma-Aldrich) and the PhosSTOP phosphatase inhibitor cocktail (Roche, Tokyo, Japan). The protein concentration of the samples was determined with the BCA assay kit (23225; Thermo Fisher Scientific Inc.). An equal amount of extracted proteins was separated on $10 \%$ SDS-PAGE Gel, and transferred onto PVDF membrane (162-0177; Bio-Rad Inc., Hercules, CA, USA) [65]. The membranes were blocked and incubated in the indicated primary antibody, followed by the appropriate HRP-conjugated secondary antibody. The bands detected by chemiluminescence (Thermo Fisher Scientific Inc.). The primary antibodies used are; LC3 (ab51520, Abcam, Cambridge, MA, USA), and $\beta$-actin (Sigma Chemical, St Louis, MO, USA).

\section{Statistics}

The statistical analyses of experiments were performed using the Mann-Whitney $U$ test between 2 groups or one-way ANOVA with the Turkey-Kramer's test between 3 or more groups. Data analysis was performed with JMP V 13 statistical software (SAS Campus Drive, Cary, NC). All data were expressed as the mean \pm SD. Statistical differences were considered as significant with a $P$ value $<0.05$.

\section{Abbreviations}

$\alpha$-SMA: $\alpha$-smooth muscle actin; CAF: cancerassociated fibroblast; CCK8: cell-counting kit-8; Colla1: collagen type 1; CRC: colorectal cancer; CRLM: colorectal liver metastasis; CM: conditioned medium; DMEM: Dulbeccoss Modified Eagle Medium; ERK: extracellular-regulated kinase; FBS: fetal bovine serum; GAPDH: gyceraldehyde-3-Phosphate Dehydrogenase; HSCs: hepatic stellate cells; IgG: immunoglobulin G; IL-6: interleukin-6; Jak2: janus kinase 2; LXRs: liver X receptors; mRNA: messenger RNA; LC3: microtubuleassociated protein 1A/1B-light chain 3; Nrf2: nuclear factor erythroid 2-related factor 2; PD-L1: programmed cell death ligand 1; ROS: reactive oxygen species; Stat3: signal transducer and activator of transcription 3; Timp1: tissue inhibitor of metalloproteinase 1; TLR4: tolllike receptor 4; TGF- $\beta$ : transforming growth factor $\beta$; 
Daikenchuto: TU-100; ULK: UNC51-like kinase; VEGF: vascular endothelial growth factor.

\section{Author contributions}

Y.W, Y.M, and M.S designed the study. Y.W, K.T, S.O, S.Y, Y.S, and S.Y performed experiments. S.I, T.I, Y.M, and M.S supervised the study. All authors discussed the results.

\section{ACKNOWLEDGMENTS}

This study was supported by a Grant from the Tsumura. \& Co., Research Program on Hepatitis from the Japan Agency for Medical Research and Development (AMED) Grant Numbers JP19fk0210048 and JP20fk0210048, and Grant-in-Aid for Scientific Research (Grant no. 20K08957 to Y.M and 18K02871 to S.M). We thank Ms. Yumi Horikawa for the support in the performance of this study.

\section{CONFLICTS OF INTEREST}

We state any potential conflicts of interest regarding our study as follows; Mitsuo Shimada received grant support from Tsumura \& Co. The other authors declare no conflicts of interest in association with the present study.

\section{REFERENCES}

1. Bhandari A, Woodhouse M, Gupta S. Colorectal cancer is a leading cause of cancer incidence and mortality among adults younger than 50 years in the USA: a SEER-based analysis with comparison to other young-onset cancers. J Investig Med. 2017; 65:311-5. https://doi.org/10.1136/jim-2016-000229. [PubMed]

2. Keum N, Giovannucci E. Global burden of colorectal cancer: emerging trends, risk factors and prevention strategies. Nat Rev Gastroenterol Hepatol. 2019; 16:71332. https://doi.org/10.1038/s41575-019-0189-8. [PubMed]

3. Siegel RL, Miller KD, Goding Sauer A, Fedewa SA, Butterly LF, Anderson JC, Cercek A, Smith RA, Jemal A. Colorectal cancer statistics, 2020. CA Cancer J Clin. 2020; 70:145-64. https://doi.org/10.3322/caac.21601. [PubMed]

4. van de Velde CJ, Boelens PG, Borras JM, Coebergh JW, Cervantes A, Blomqvist L, Beets-Tan RG, van den Broek CB, Brown G, Van Cutsem E, Espin E, Haustermans K, Glimelius B, et al. EURECCA colorectal: multidisciplinary management: European consensus conference colon \& rectum. Eur J Cancer. 2014; 50:1.e-.e34. https://doi. org/10.1016/j.ejca.2013.06.048. [PubMed]

5. Sievers CK, Kratz JD, Zurbriggen LD, LoConte NK, Lubner SJ, Uboha N, Mulkerin D, Matkowskyj KA, Deming DA. The Multidisciplinary Management of Colorectal Cancer: Present and Future Paradigms. Clin Colon Rectal Surg.
2016; 29:232-8. https://doi.org/10.1055/s-0036-1584292. [PubMed]

6. Harvey AL, Edrada-Ebel R, Quinn RJ. The re-emergence of natural products for drug discovery in the genomics era. Nat Rev Drug Discov. 2015; 14:111-29. https://doi.org/10.1038/ nrd4510. [PubMed]

7. Surh YJ. Cancer chemoprevention with dietary phytochemicals. Nat Rev Cancer. 2003; 3:768-80. https:// doi.org/10.1038/nrc1189. [PubMed]

8. Hosaka M, Arai I, Ishiura Y, Ito T, Seki Y, Naito T, Masuzawa Y, Nakayama T, Motoo Y. Efficacy of daikenchuto, a traditional Japanese Kampo medicine, for postoperative intestinal dysfunction in patients with gastrointestinal cancers: meta-analysis. Int J Clin Oncol. 2019; 24:1385-96. https://doi.org/10.1007/s10147-019-01502-1. [PubMed]

9. Katsuno H, Maeda K, Kaiho T, Kunieda K, Funahashi K, Sakamoto J, Kono T, Hasegawa H, Furukawa Y, Imazu Y, Morita S, Watanabe M. Clinical efficacy of Daikenchuto for gastrointestinal dysfunction following colon surgery: a randomized, double-blind, multicenter, placebo-controlled study (JFMC39-0902). Jpn J Clin Oncol. 2015; 45:650-6. https://doi.org/10.1093/jico/hyv056. [PubMed]

10. Kono T, Kanematsu T, Kitajima M. Exodus of Kampo, traditional Japanese medicine, from the complementary and alternative medicines: is it time yet? Surgery. 2009; 146:837-40. https://doi.org/10.1016/j.surg.2009.06.012. [PubMed]

11. Kono T, Shimada M, Nishi M, Morine Y, Yoshikawa K, Katsuno H, Maeda K, Koeda K, Morita S, Watanabe M, Kusano M, Sakamoto J, Saji S, et al. Daikenchuto accelerates the recovery from prolonged postoperative ileus after open abdominal surgery: a subgroup analysis of three randomized controlled trials. Surg Today. 2019; 49:704-11. https://doi.org/10.1007/s00595-019-01787-9. [PubMed]

12. Okada K, Kawai M, Hirono S, Fujii T, Kodera Y, Sho M, Nakajima Y, Satoi S, Kwon AH, Shimizu Y, Ambo Y, Kondo N, Murakami Y, et al. Evaluation of the efficacy of daikenchuto (TJ -100) for the prevention of paralytic ileus after pancreaticoduodenectomy: A multicenter, doubleblind, randomized, placebo-controlled trial. Surgery. 2016; 159:1333-41. https://doi.org/10.1016/j.surg.2015.11.019. [PubMed]

13. Shimada M, Morine Y, Nagano H, Hatano E, Kaiho T, Miyazaki M, Kono T, Kamiyama T, Morita S, Sakamoto J, Kusano M, Saji S, Kanematsu T, et al. Effect of TU-100, a traditional Japanese medicine, administered after hepatic resection in patients with liver cancer: a multi-center, phase III trial (JFMC40-1001). Int J Clin Oncol. 2015; 20:95-104. https://doi.org/10.1007/s10147-014-0678-2. [PubMed]

14. Yoshikawa K, Shimada M, Wakabayashi G, Ishida K, Kaiho T, Kitagawa Y, Sakamoto J, Shiraishi N, Koeda K, Mochiki E, Saikawa Y, Yamaguchi K, Watanabe M, et al. Effect of Daikenchuto, a Traditional Japanese Herbal Medicine, after Total Gastrectomy for Gastric Cancer: A Multicenter, Randomized, Double-Blind, Placebo-Controlled, Phase 
II Trial. J Am Coll Surg. 2015; 221:571-8. https://doi. org/10.1016/j.jamcollsurg.2015.03.004. [PubMed]

15. Kono T, Omiya Y, Hira Y, Kaneko A, Chiba S, Suzuki T, Noguchi M, Watanabe T. Daikenchuto (TU-100) ameliorates colon microvascular dysfunction via endogenous adrenomedullin in Crohn's disease rat model. J Gastroenterol. 2011; 46:1187-96. https://doi.org/10.1007/ s00535-011-0438-2. [PubMed]

16. Hasebe T, Matsukawa J, Ringus D, Miyoshi J, Hart J, Kaneko A, Yamamoto M, Kono T, Fujiya M, Kohgo Y, Wang CZ, Yuan CS, Bissonnette M, et al. Daikenchuto (TU100) Suppresses Tumor Development in the Azoxymethane and $\mathrm{APC}(\mathrm{min} /+)$ Mouse Models of Experimental Colon Cancer. Phytother Res. 2017; 31:90-9. https://doi. org/10.1002/ptr.5735. [PubMed]

17. Iwasa $\mathrm{T}$, Ogino $\mathrm{H}$, Nakamura $\mathrm{K}$, Ihara $\mathrm{E}$, Akiho $\mathrm{H}$, Takayanagi R. Feeding administration of Daikenchuto suppresses colitis induced by naive CD4+ T cell transfer into SCID mice. Dig Dis Sci. 2012; 57:2571-9. https://doi. org/10.1007/s10620-012-2218-0. [PubMed]

18. Kono T, Kaneko A, Hira Y, Suzuki T, Chisato N, Ohtake N, Miura N, Watanabe T. Anti-colitis and -adhesion effects of daikenchuto via endogenous adrenomedullin enhancement in Crohn's disease mouse model. J Crohns Colitis. 2010; 4:161-70. https://doi.org/10.1016/j.crohns.2009.09.006. [PubMed]

19. Nagata T, Toume K, Long LX, Hirano K, Watanabe T, Sekine S, Okumura T, Komatsu K, Tsukada K. Anticancer effect of a Kampo preparation Daikenchuto. J Nat Med. 2016; 70:627-33. https://doi.org/10.1007/s11418-0160989-x. [PubMed]

20. Ueno N, Hasebe T, Kaneko A, Yamamoto M, Fujiya M, Kohgo Y, Kono T, Wang CZ, Yuan CS, Bissonnette M, Chang EB, Musch MW. TU-100 (Daikenchuto) and ginger ameliorate anti-CD3 antibody induced $\mathrm{T}$ cell-mediated murine enteritis: microbe-independent effects involving Akt and NF-אB suppression. PLoS One. 2014; 9:e97456. https:// doi.org/10.1371/journal.pone.0097456. [PubMed]

21. Yoshikawa K, Kurita N, Higashijima J, Miyatani T, Miyamoto H, Nishioka M, Shimada M. Kampo medicine "Dai-kenchu-to" prevents bacterial translocation in rats. Dig Dis Sci. 2008; 53:1824-31. https://doi.org/10.1007/s10620008-0281-3. [PubMed]

22. Affo S, Yu LX, Schwabe RF. The Role of CancerAssociated Fibroblasts and Fibrosis in Liver Cancer. Annu Rev Pathol. 2017; 12:153-86. https://doi.org/10.1146/ annurev-pathol-052016-100322. [PubMed]

23. Brodt P. Role of the Microenvironment in Liver Metastasis: From Pre- to Prometastatic Niches. Clin Cancer Res. 2016; 22:5971-82. https://doi.org/10.1158/1078-0432.ccr-160460. [PubMed]

24. Eggert T, Greten TF. Tumor regulation of the tissue environment in the liver. Pharmacol Ther. 2017; 173:4757. https://doi.org/10.1016/j.pharmthera.2017.02.005. [PubMed]
25. Feng R, Morine $Y$, Ikemoto T, Imura S, Iwahashi S, Saito Y, Shimada M. Nab-paclitaxel interrupts cancer-stromal interaction through C-X-C motif chemokine 10-mediated interleukin-6 downregulation in vitro. Cancer Sci. 2018; 109:2509-19. https://doi.org/10.1111/cas.13694. [PubMed]

26. Feng R, Morine Y, Ikemoto T, Imura S, Iwahashi S, Saito Y, Shimada M. Nrf2 activation drive macrophages polarization and cancer cell epithelial-mesenchymal transition during interaction. Cell Commun Signal. 2018; 16:54. https://doi. org/10.1186/s12964-018-0262-x. [PubMed]

27. Quail DF, Joyce JA. Microenvironmental regulation of tumor progression and metastasis. Nat Med. 2013; 19:142337. https://doi.org/10.1038/nm.3394. [PubMed]

28. Huang WH, Zhou MW, Zhu YF, Xiang JB, Li ZY, Wang ZH, Zhou YM, Yang Y, Chen ZY, Gu XD. The Role Of Hepatic Stellate Cells In Promoting Liver Metastasis Of Colorectal Carcinoma. Onco Targets Ther. 2019; 12:757380. https://doi.org/10.2147/ott.s214409. [PubMed]

29. Yada K, Ishibashi H, Mori H, Morine Y, Zhu C, Feng R, Kono T, Shimada M. The Kampo medicine "Daikenchuto (TU-100)" prevents bacterial translocation and hepatic fibrosis in a rat model of biliary atresia. Surgery. 2016; 159:1600-11. https://doi.org/10.1016/j.surg.2016.02.002. [PubMed]

30. Hamada S, Masamune A, Yoshida N, Takikawa T, Shimosegawa T. IL-6/STAT3 Plays a Regulatory Role in the Interaction Between Pancreatic Stellate Cells and Cancer Cells. Dig Dis Sci. 2016; 61:1561-71. https://doi. org/10.1007/s10620-015-4001-5. [PubMed]

31. Micke P, Ostman A. Exploring the tumour environment: cancer-associated fibroblasts as targets in cancer therapy. Expert Opin Ther Targets. 2005; 9:1217-33. https://doi. org/10.1517/14728222.9.6.1217. [PubMed]

32. Kuang P, Zhao W, Su W, Zhang Z, Zhang L, Liu J, Ren G, Yin Z, Wang X. 18ß-glycyrrhetinic acid inhibits hepatocellular carcinoma development by reversing hepatic stellate cellmediated immunosuppression in mice. Int J Cancer. 2013; 132:1831-41. https://doi.org/10.1002/ijc.27852. [PubMed]

33. Hautekeete ML, Geerts A. The hepatic stellate (Ito) cell: its role in human liver disease. Virchows Arch. 1997; 430:195207. https://doi.org/10.1007/bf01324802. [PubMed]

34. Lee MS, Kim MS, Yoo JK, Lee JY, Ju JE, Jeong YK. Enhanced anticancer effects of a mixture of low-dose mushrooms and Panax ginseng root extracts in human colorectal cancer cells. Oncol Rep. 2017; 38:1597-604. https://doi.org/10.3892/or.2017.5796. [PubMed]

35. Liu Y, Fan D. Ginsenoside Rg5 induces apoptosis and autophagy via the inhibition of the PI3K/Akt pathway against breast cancer in a mouse model. Food Funct. 2018; 9:5513-27. https://doi.org/10.1039/c8fo01122b. [PubMed]

36. Nozaki R, Kono T, Bochimoto H, Watanabe T, Oketani K, Sakamaki Y, Okubo N, Nakagawa K, Takeda H. Zanthoxylum fruit extract from Japanese pepper promotes autophagic cell death in cancer cells. Oncotarget. 2016; 
7:70437-46. https://doi.org/10.18632/oncotarget.11926. [PubMed]

37. Yoo HS, Kim JM, Jo E, Cho CK, Lee SY, Kang HS, Lee MG, Yang PY, Jang IS. Modified Panax ginseng extract regulates autophagy by AMPK signaling in A549 human lung cancer cells. Oncol Rep. 2017; 37:3287-96. https://doi. org/10.3892/or.2017.5590. [PubMed]

38. Zhang XY, Sun K, Zhu Q, Song T, Liu Y. Ginseng polysaccharide serves as a potential radiosensitizer through inducing apoptosis and autophagy in the treatment of osteosarcoma. Kaohsiung J Med Sci. 2017; 33:535-42. https://doi.org/10.1016/j.kjms.2017.07.001. [PubMed]

39. Zheng X, Chen W, Hou H, Li J, Li H, Sun X, Zhao L, Li X. Ginsenoside 20(S)-Rg3 induced autophagy to inhibit migration and invasion of ovarian cancer. Biomed Pharmacother. 2017; 85:620-6. https://doi.org/10.1016/j. biopha.2016.11.072. [PubMed]

40. Russell RC, Tian Y, Yuan H, Park HW, Chang YY, Kim J, Kim H, Neufeld TP, Dillin A, Guan KL. ULK1 induces autophagy by phosphorylating Beclin-1 and activating VPS34 lipid kinase. Nat Cell Biol. 2013; 15:741-50. https:// doi.org/10.1038/ncb2757. [PubMed]

41. Vázquez P, Arroba AI, Cecconi F, de la Rosa EJ, Boya P, de Pablo F. Atg5 and Ambra1 differentially modulate neurogenesis in neural stem cells. Autophagy. 2012; 8:18799. https://doi.org/10.4161/auto.8.2.18535. [PubMed]

42. Fujiki K, Nakamura M, Matsuda T, Isogai M, Ikeda M, Yamamoto Y, Kitamura M, Sazaki N, Yakushiji F, Suzuki S, Tomiyama J, Uchida T, Taniguchi K. IL-12 and IL-18 induction and subsequent NKT activation effects of the Japanese botanical medicine Juzentaihoto. Int J Mol Sci. 2008; 9:1142-55. https://doi.org/10.3390/ijms9071142. [PubMed]

43. Oka H, Yamamoto S, Kuroki T, Harihara S, Marumo T, Kim SR, Monna T, Kobayashi K, Tango T. Prospective study of chemoprevention of hepatocellular carcinoma with Sho-saiko-to (TJ-9). Cancer. 1995; 76:743-9. https:// doi.org/10.1002/1097-0142(19950901)76:5<743::aidcncr2820760506>3.0.co;2-v. [PubMed]

44. Saiki I. A Kampo medicine "Juzen-taiho-to"--prevention of malignant progression and metastasis of tumor cells and the mechanism of action. Biol Pharm Bull. 2000; 23:677-88. https://doi.org/10.1248/bpb.23.677. [PubMed]

45. Gupta S, Jain A, Syed SN, Snodgrass RG, Pflüger-Müller B, Leisegang MS, Weigert A, Brandes RP, Ebersberger I, Brüne B, Namgaladze D. IL-6 augments IL-4-induced polarization of primary human macrophages through synergy of STAT3, STAT6 and BATF transcription factors. Oncoimmunology. 2018; 7:e1494110. https://doi.org/10.10 80/2162402x.2018.1494110. [PubMed]

46. Karakasheva TA, Lin EW, Tang Q, Qiao E, Waldron TJ, Soni M, Klein-Szanto AJ, Sahu V, Basu D, Ohashi S, Baba K, Giaccone ZT, Walker SR, et al. IL-6 Mediates CrossTalk between Tumor Cells and Activated Fibroblasts in the Tumor Microenvironment. Cancer Res. 2018; 78:4957-70. https://doi.org/10.1158/0008-5472.can-17-2268. [PubMed]
47. Ohno Y, Toyoshima Y, Yurino H, Monma N, Xiang H, Sumida K, Kaneumi S, Terada S, Hashimoto S, Ikeo K, Homma S, Kawamura H, Takahashi N, et al. Lack of interleukin-6 in the tumor microenvironment augments type-1 immunity and increases the efficacy of cancer immunotherapy. Cancer Sci. 2017; 108:1959-66. https:// doi.org/10.1111/cas.13330. [PubMed]

48. Iwahasi S, Rui F, Morine Y, Yamada S, Saito YU, Ikemoto T, Imura S, Shimada M. Hepatic Stellate Cells Contribute to the Tumor Malignancy of Hepatocellular Carcinoma Through the IL-6 Pathway. Anticancer Res. 2020; 40:7439. https://doi.org/10.21873/anticanres.14005. [PubMed]

49. Li JP, Gao Y, Chu SF, Zhang Z, Xia CY, Mou Z, Song XY, He WB, Guo XF, Chen NH. Nrf2 pathway activation contributes to anti-fibrosis effects of ginsenoside $\operatorname{Rg} 1$ in a rat model of alcohol- and CCl4-induced hepatic fibrosis. Acta Pharmacol Sin. 2014; 35:1031-44. https://doi. org/10.1038/aps.2014.41. [PubMed]

50. Hui J, Gao J, Wang Y, Zhang J, Han Y, Wei L, Liu X, Wu J. Panax notoginseng saponins ameliorates experimental hepatic fibrosis and hepatic stellate cell proliferation by inhibiting the Jak2/ Stat3 pathways. J Tradit Chin Med. 2016; 36:217-24. https://doi.org/10.1016/s02546272(16)30030-9. [PubMed]

51. Ohsumi Y. Molecular dissection of autophagy: two ubiquitin-like systems. Nat Rev Mol Cell Biol. 2001; 2:211-6. https://doi.org/10.1038/35056522. [PubMed]

52. Pan H, Chen L, Xu Y, Han W, Lou F, Fei W, Liu S, Jing Z, Sui X. Autophagy-associated immune responses and cancer immunotherapy. Oncotarget. 2016; 7:21235-46. https://doi. org/10.18632/oncotarget.6908. [ [PubMed]

53. Degenhardt K, Mathew R, Beaudoin B, Bray K, Anderson D, Chen G, Mukherjee C, Shi Y, Gélinas C, Fan Y, Nelson DA, Jin S, White E. Autophagy promotes tumor cell survival and restricts necrosis, inflammation, and tumorigenesis. Cancer Cell. 2006; 10:51-64. https://doi. org/10.1016/j.ccr.2006.06.001. [PubMed]

54. Kimura T, Takabatake Y, Takahashi A, Isaka Y. Chloroquine in cancer therapy: a double-edged sword of autophagy. Cancer Res. 2013; 73:3-7. https://doi.org/10.1158/00085472.can-12-2464. [PubMed]

55. White E. The role for autophagy in cancer. J Clin Invest. 2015; 125:42-6. https://doi.org/10.1172/jci73941. [PubMed]

56. Kim LH, Khadka S, Shin JA, Jung JY, Ryu MH, Yu HJ, Lee HN, Jang B, Yang IH, Won DH, Kwon HJ, Jeong JH, Hong $\mathrm{SD}$, et al. Nitidine chloride acts as an apoptosis inducer in human oral cancer cells and a nude mouse xenograft model via inhibition of STAT3. Oncotarget. 2017; 8:91306-15. https://doi.org/10.18632/oncotarget.20444. [PubMed]

57. Kiyama R. Nutritional implications of ginger: chemistry, biological activities and signaling pathways. J Nutr Biochem. 2020; 86:108486. https://doi.org/10.1016/j. inutbio.2020.108486. [PubMed]

58. Hasegawa $\mathrm{H}$. Proof of the mysterious efficacy of ginseng: basic and clinical trials: metabolic activation of ginsenoside: 
deglycosylation by intestinal bacteria and esterification with fatty acid. J Pharmacol Sci. 2004; 95:153-7. https://doi. org/10.1254/jphs.fmj04001x4. [PubMed]

59. Kang KA, Piao MJ, Kim KC, Zheng J, Yao CW, Cha JW, Kim HS, Kim DH, Bae SC, Hyun JW. Compound K, a metabolite of ginseng saponin, inhibits colorectal cancer cell growth and induces apoptosis through inhibition of histone deacetylase activity. Int J Oncol. 2013; 43:1907-14. https://doi.org/10.3892/ijo.2013.2129. [ubMed]

60. Zhang Z, Du GJ, Wang CZ, Wen XD, Calway T, Li Z, He TC, Du W, Bissonnette M, Musch MW, Chang EB, Yuan CS. Compound K, a Ginsenoside Metabolite, Inhibits Colon Cancer Growth via Multiple Pathways Including p53-p21 Interactions. Int J Mol Sci. 2013; 14:2980-95. https://doi. org/10.3390/ijms 14022980. [PubMed]

61. Yang Y, Ikezoe T, Takeuchi T, Adachi Y, Ohtsuki Y, Koeffler HP, Taguchi H. Zanthoxyli Fructus induces growth arrest and apoptosis of LNCaP human prostate cancer cells in vitro and in vivo in association with blockade of the AKT and AR signal pathways. Oncol Rep. 2006; 15:1581-90. https://doi.org/10.3892/or.15.6.1581. [PubMed]

62. Cui X, Jin Y, Poudyal D, Chumanevich AA, Davis T, Windust A, Hofseth A, Wu W, Habiger J, Pena E, Wood P, Nagarkatti M, Nagarkatti PS, et al. Mechanistic insight into the ability of American ginseng to suppress colon cancer associated with colitis. Carcinogenesis. 2010; 31:1734-41. https://doi.org/10.1093/carcin/bgq163. [PubMed]
63. Kono T, Kaneko A, Omiya Y, Ohbuchi K, Ohno N, Yamamoto M. Epithelial transient receptor potential ankyrin 1 (TRPA1)-dependent adrenomedullin upregulates blood flow in rat small intestine. Am J Physiol Gastrointest Liver Physiol. 2013; 304:G428-36. https://doi.org/10.1152/ ajpgi.00356.2012. [PubMed]

64. Liang CC, Park AY, Guan JL. In vitro scratch assay: a convenient and inexpensive method for analysis of cell migration in vitro. Nat Protoc. 2007; 2:329-33. https://doi. org/10.1038/nprot.2007.30. [PubMed]

65. Dougherty U, Mustafi R, Wang Y, Musch MW, Wang CZ, Konda VJ, Kulkarni A, Hart J, Dawson G, Kim KE, Yuan CS, Chang EB, Bissonnette M. American ginseng suppresses Western diet-promoted tumorigenesis in model of inflammation-associated colon cancer: role of EGFR. BMC Complement Altern Med. 2011; 11:111. https://doi. org/10.1186/1472-6882-11-111. [PubMed] 